1 Sutedja T, vd Heyden A, van Mourik J, Postmus PE. Haemoptysis and wheezing in a young
woman. Case for diagnosis. Eur Respir $\mathcal{f}$ (in woman.

2 Sutedja TG, Kwa B, van Kamp H, van Zandwijk N. Ph, $\mathrm{Kwa}$, , van Kamp H, van Zandwijk $N$. Photodynamic therapy as an alternative for surgery in a patient with lung cancer undergoing bone marrow

3 Edell ES, Cortese DA. Photodynamic therapy in the management of early superficial squamous cell carcinoma as an alternative to surgical resection. Chest 1992;102:1319-22.

AUTHORS' REPLY We were very interested to read the letter by Dr Postmus et al. This case report is very encouraging since it supports the findings in our animal study.

It is, of course, worrying that a fibrotic stenosis developed after treatment, but this may have been due to the preliminary treatment with the NdYAG laser and not the PDT.

PDT with haematoporphyrin derivative or phthalocyanines does, nevertheless, cause some fibrosis, but we are currently studying, in the same animal model, the role of amino laevulinic acid (ALA), a natural precursor in the synthesis of haem. When given in excess this leads to an accumulation of protoporphyrin IX, which is an effective photosensitiser when illuminated with red laser light. ALA appears to have much better selectivity for tumour cells and for mucosa and may therefore give a much better result than is currently possible.

M R HETZEL Department of Thoracic Medicine,
Middlesex Hospital, Middlesex Hospital,
London W1N $8 A A$

\section{Variability in ciliary beat frequency in bronchiectasis}

\section{Reversal of bleomycin lung toxicity with corticosteroids}

In their paper Drs Maher and Daly (January 1993;48:92-4) describe the case of a man with interstitial changes in the lungs after bleomycin treatment in whom they obtained a reduction in clinical symptoms and an improvement in the chest radiograph after long term high dose corticosteroids plus azathioprine. They also measured an improvement in the lung function with total lung capacity becoming normal and an increase of more than $50 \%$ in the carbon monoxide transfer factor ( $T_{\text {LCO }}$ ).

I would like to supplement these observations with the case of a 42 year old patient who developed interstitial changes as a result of bleomycin treatment for Hodgkin's disease. Symptoms began to appear a few months after completion of treatment, which included $420 \mathrm{mg}$ bleomycin. Prednisolone $(1 \mathrm{mg} / \mathrm{kg})$ was given and the lung function

changes are shown in the table. After one month of treatment there was a reduction in clinical symptoms and an improvement in the chest radiograph, as well as a return to normal of spirometric values and an improvement in the TLCO.

It has been stressed that TLCO is a more sensitive parameter of lung damage than vital capacity after bleomycin. ${ }^{12}$ The improvement in diffusion seen in the patient treated by Drs Maher and Daly also suggests improvement in the interstitial changes. However, the continuing reduced TLCO indicates that there was residual damage. This was confirmed in our case by a reduction in static compliance. It appears that static compliance in these patients may be a useful measurement of persistence of interstitial changes in patients treated with bleomycin.

$$
\begin{array}{r}
\text { J KOZIELSKI } \\
\text { Department of } \\
\text { Pneumonology, } \\
\text { Sil Medical Academy, } \\
\text { ul, Koziolka 1, } \\
41-803 \text { Zabrze, } \\
\text { Poland }
\end{array}
$$

1 Comis RL, Kuppinger MS, Ginsberg SJ, et al. Role of single breath carbon monoxide diffusing capacity in monitoring the pulmonary effects of bleomycin in germ tumor patients. Cancer Res 1979;39:5076-80.

2 Ginsberg SJ, Comis RL. The pulmonary toxicity of antineoplastic agents. Semin Oncol 1982, 9:34-51.

I read with great interest the paper by $\mathrm{Dr}$ D Veale and coworkers (October 1993; 48:1018-20) in which the authors reported results on the in vitro variability of nasal ciliary beat frequency (CBF) in normal subjects and bronchiectatic patients. In $1990 \mathrm{my}$ group conducted a study in which the variability of nasal CBF was investigated in healthy

subjects.' Samples of nasal epithelium were collected and transferred to either sealed microscope coverslip slide preparations or tissue culture chamber. By using a photometric technique and rigorous randomisation criteria for the measurements, the intracell, intrasubject, and intersubject variability of $\mathrm{CBF}$ was assessed, both at room temperature and $37^{\circ} \mathrm{C}$. At $37^{\circ} \mathrm{C}$ the results showed mean coefficients of variation of $4 \%$ (intracell), $17 \%$ (intrasubject), and $11 \%$ (intersubject; $\mathrm{n}=10$ ). Although differences in methodology make it difficult to compare our results with those obtained by Dr Veale's group, both studies underline the necessity of standardised criteria of investigation when assessing ciliary function. The wider ques-

Lung function parameters in patients with interstitial lung changes as a function of the duration of the disease and treatment

\begin{tabular}{lllll}
\hline $\begin{array}{l}\text { Timing of } \\
\text { examination }\end{array}$ & $\begin{array}{l}\text { FVC } \\
\text { (\% pred) }\end{array}$ & $\begin{array}{l}\text { TLCO } \\
\text { (\% pred) }\end{array}$ & $\begin{array}{l}\text { Compliance } \\
\text { (\% pred })\end{array}$ & $\begin{array}{l}\text { Dosage } \\
\text { of prednisolone }\end{array}$ \\
\hline On admission & 59 & 39 & $16 \cdot 3$ & $50 \mathrm{mg} /$ day \\
One week & 75 & -71 & 33 & $50 \mathrm{mg} / \mathrm{day}$ \\
One month & 93 & - & - & $50 \mathrm{mg} /$ day \\
Three months & 93 & 80 & 34 & $10 \mathrm{mg} /$ day \\
Seven months & 100 & &
\end{tabular}

FVC = functional vital capacity; TLCO = carbon monoxide transfer factor. tion remains as to when a small but statistically significant difference in $\mathrm{CBF}$ in vitro also constitutes a physiologically meaningful difference in vivo.

G DI BENEDETTO Department of Thoracic Medicine, The Royal Free Hospital, Pond Street,

$$
\text { London NW3 } 2 Q G
$$

1 Di Benedetto G, Manara-Shediac FS, Mehta A. Variability of human ciliary beat frequency in vitro. Eur Respir f 1990;3(Suppl 10):257S.

\section{BOOK NOTICE}

Pulmonary Radiology. EJ Potchen, RG Grainger and $R$ Greene. (Pp 412; £57.00) Philadelphia: Saunders, 1993. 0721648215.

The Fleischner Society was named after the late Felix Fleischner in recognition of his outstanding contribution to the development of chest radiology. One of the Society's aims was to have a multidisciplinary approach to give a better understanding of disease processes to chest radiologists. The original contributions were published in Frontiers of Pulmonary Radiology.

Pulmonary Radiology is the second book published by the Society and exemplifies this multidisciplinary approach throughout the chapters which include: The developing lung; Interstitial lung diseases; Lung transplantation; Vascular diseases; The pleura; Acute lung injury; Airway disease; AIDS; Lung cancer; and New imaging modalities.

This is an excellent book which is intended to update and inform rather than being comprehensive, and is written by experts who explain the radiological appearances on the basis of morphology and pathophysiology. Not only does it do this, but it is a pleasure to read.

The chapter on Pathology of the developing lung by Lynne Reid is dealt with in a very clear and comprehensive way, aided by excellent illustrations and line drawings. I also enjoyed the chapter on Problems and pitfalls in the early diagnosis of lung cancer which is an excellent review, and the informative and refreshing way in which such a basic topic as lobar collapse is discussed. Lung physiology features highly, particularly in the section on acute lung injury, but such is the wealth of experience of the authors and variety of the subject matter that I am sure all chest physicians or radiologists who read this book will have their understanding or knowledge enhanced.

The book is well referenced, up to date, and has a comprehensive index. The illustrations are of a very high standard and all imaging modalities are included. The role of MRI in chest radiology is well presented, and there is an interesting final section on current concepts in thoracic CT scanning which includes spiral scanning, 3D reconstructions of the central airways, and the possibilities for physiological scanning.

This book should be an essential purchase to all thoracic and imaging departments at only $£ 57$, and I recommend it unreservedly to all those interested in a better understanding of chest radiology. - PS 